\title{
Effects of polar protic solvents on dual emissions of 3-hydroxychromones
}

\author{
ANDREY S KLYMCHENKO, ${ }^{\mathrm{a}, *}$ CYRIL KENFACK, ${ }^{\mathrm{a}, \mathrm{b}}$ GUY DUPORTAIL ${ }^{\mathrm{a}}$ and \\ YVES MÉLY ${ }^{\mathrm{a}, *}$ \\ ${ }^{a}$ Photophysique des Interactions Biomoléculaires, UMR 7175 CNRS, Institut Gilbert Laustriat, Faculté de \\ Pharmacie, Université Louis Pasteur, Strasbourg 1, 74, Route du Rhin, 67401 Illkirch Cedex, France \\ ${ }^{\mathrm{b}}$ Centre de Physique Atomique Moléculaire et Optique Quantique, Faculté des Sciences, Université de \\ Douala. BP 8580, Douala, Cameroun \\ e-mail: \{aklymchenko, yves.mely\}@pharma.u-strasbg.fr
}

\begin{abstract}
Hydroxychromones (3HC), exhibit dual emissions highly sensitive to solvent properties due to excited state intramolecular proton transfer (ESIPT). Therefore, 3HCs find wide applications as fluorescence probes in biological systems. Here, it is particularly important to understand the fluorescence behaviour of $3 \mathrm{HCs}$ in polar environments. Herein, we studied 3-hydroxyflavone, 2-(2-furyl)-3hydroxychromone and 2-(2-benzofuryl)-3-hydroxychromone in high polarity solvents characterized by different H-bond donor abilities, donor concentrations and acceptor abilities. Our results show that the dual emissions of the dyes are insensitive to solvent basicity but strongly depend on the two other parameters. Moreover, furyl- and benzofuryl-substituted dyes were significantly more sensitive than the 3hydroxyflavone to H-bond donor ability, while all three dyes showed roughly equivalent high sensitivity to H-bond donor concentration. These results can be explained by different mechanisms. Thus, the sensitivity of all three dyes to increasing concentrations of $\mathrm{H}$-bond donors probably results from increase in the population of solvated dye with disrupted intramolecular H-bonds. Meantime, the sensitivity to Hbond donor ability of the solvent, observed mainly with furyl and benzofuryl dyes, is probably related to the strength of the H-bonds between the solvent and the 4-carbonyl group of the dye with intact intramolecular H-bonds. The present results provide new insights for further applications of $3 \mathrm{HC}$ derivatives as environment-sensitive probes and labels of biological molecules.
\end{abstract}

Keywords. Polar protic solvents; dual emission; 3-hydroxychromones; excited state intramolecular proton transfer.

\section{Introduction}

3-Hydroxychromones (3HCs) have attracted considerable interest in recent years due to their photochemistry and potential applications. These dyes exhibit dual emission due to excited state intramolecular proton transfer (ESIPT) that results in two forms in the excited state: a normal $\left(\mathrm{N}^{*}\right)$ and tautomer (ESIPT product, $\mathrm{T}^{*}$ ) forms (figure 1 ). ${ }^{1}$ Both the $\mathrm{N}^{*}$ and $\mathrm{T}^{*}$ forms are highly emissive, exhibiting well-separated bands in the emission spectra. Importantly, these dyes can provide information about the physicochemical properties of their microenvironment, both by the positions and the relative intensities of their two emission bands. ${ }^{2}$ Measurements of the intensity ratio of the $\mathrm{N}^{*}$ and $\mathrm{T}^{*}$ bands, $I_{\mathrm{N}^{*}} / I_{\mathrm{T}^{*}}$, are very attractive possibilities to perform ratiometric detection, inde-

\footnotetext{
*For correspondence
}

pendent of dye concentration and instrumental settings. ${ }^{3,4}$ Due to these unique features, numerous $3 \mathrm{HC}$ dyes have been synthesized and studied, resulting in the development of new fluorescent probes for solvent polarity, ${ }^{2,5,6}$ ion binding ${ }^{7}$ and electric fields ${ }^{8,9}$ with applications in the fields of polymers, ${ }^{10}$ reverse micelles, ${ }^{11,12}$ host-guest complexes ${ }^{13}$, lipid vesicles, ${ }^{9,14-17}$ cellular membranes ${ }^{18}$ and proteins. ${ }^{19-23}$ Reactive derivatives of $3 \mathrm{HCs}$ have been also proposed for fluorescence labelling of biomolecules in order to study their conformations and intermolecular interactions. ${ }^{20,21}$ In this respect, compounds $\mathbf{2}$ and $\mathbf{3}$ (chart 1) and their derivatives are very promising since they exhibit solvent-dependent dual emission and satisfactory fluorescence quantum yields in highly polar environment. ${ }^{24,25}$ Consequently, these dyes are ideal for application at the polar interfaces of biomolecules. ${ }^{21}$ Organic solvents are useful model systems to calibrate the response of environment-sensitive 
dyes to the properties of the environment ${ }^{26}$ and to explain their spectroscopic behaviour in biological systems. While the solvent dependence of the parent 2-phenyl-3-hydroxychromone (3-hydroxyflavone) 1 and its 4'-dialkylamino-derivative have been extensively studied, ${ }^{2,27,28}$ a systematic study of dyes $\mathbf{2}$ and 3 in polar environment has not been done. It has been shown that the dual emission of dyes $\mathbf{1 - 3}$ is poorly sensitive to the solvent polarity, while it can be strongly perturbed in protic solvents. ${ }^{24,29,30}$ Moreover, the positions of their $\mathrm{N}^{*}$ and $\mathrm{T}^{*}$ bands are poorly sensitive to the polarity of aprotic solvents, while in protic solvents these dyes show a blue shift in the emission of the $\mathrm{T}^{*}$ band. ${ }^{29,30}$ Protic solvents are relevant models of biological environments due to the ubiquitous presence in the latter of water, as well as amide and hydroxyl groups. In this respect, the key properties of protic media are their H-bond donor (acidicity) and acceptor (basicity) abilities ${ }^{31,32}$, as well as the concentration of $\mathrm{H}$-bond donors. These three parameters, measured in the environment of biomolecules, characterize the presence and concentration of H-bond donor-acceptor groups (amide,
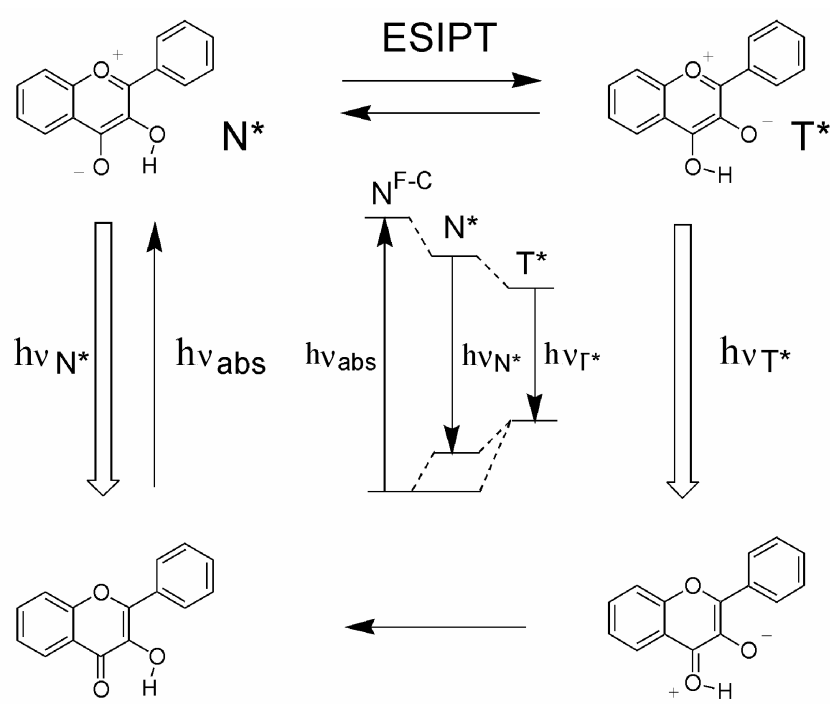

Figure 1. Scheme of the ESIPT reaction of 3-hydroxychromone, 1.

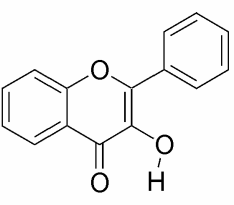

1

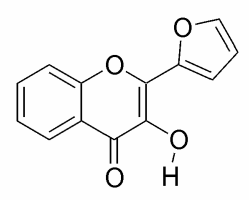

2

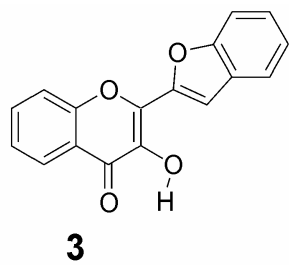

3
Chart 1. Chemical structures of the studied $3 \mathrm{HC}$ dyes. hydroxyl etc.), which could in turn be used to describe the conformational state of the biomolecules and their interactions with other biomolecules.

In the present work, we studied dyes 1-3 in highly polar solvents characterized by different $\mathrm{H}$-bond donor (acidicity, $\alpha$ ), and acceptor (basicity, $\beta$ ), abilities and the concentrations of $\mathrm{H}$-bond donors (figure 2). Our results show that the dual emissions, of dyes 1-3 are insensitive to solvent basicity but are highly affected by the other two parameters. While all three dyes show similar sensitivity to the H-bond donor concentration of the solvent, dyes 2 and $\mathbf{3}$ appear significantly more sensitive than dye 1 to the $\mathrm{H}$ bond donor ability of the solvent. The differences in sensitivities of the dyes can be explained by differences in the mechanism of perturbation of their ESIPT reaction by protic solvents. These results provide interesting insights for further applications of these dyes and their derivatives as environmentsensitive probes and labels of biological molecules.

\section{Materials and methods}

Absorption and fluorescence spectra were recorded on a Cary 400 spectrophotometer (Varian) and FluoroMax 3 spectrofluorimeter (Jobin Yvon, Horiba), respectively. All solvents were of spectroscopic grade. Flavone 1 was purchased from Aldrich Chemical Company. Chromones $\mathbf{2}$ and $\mathbf{3}$ were prepared as described elsewhere. ${ }^{24,30}$

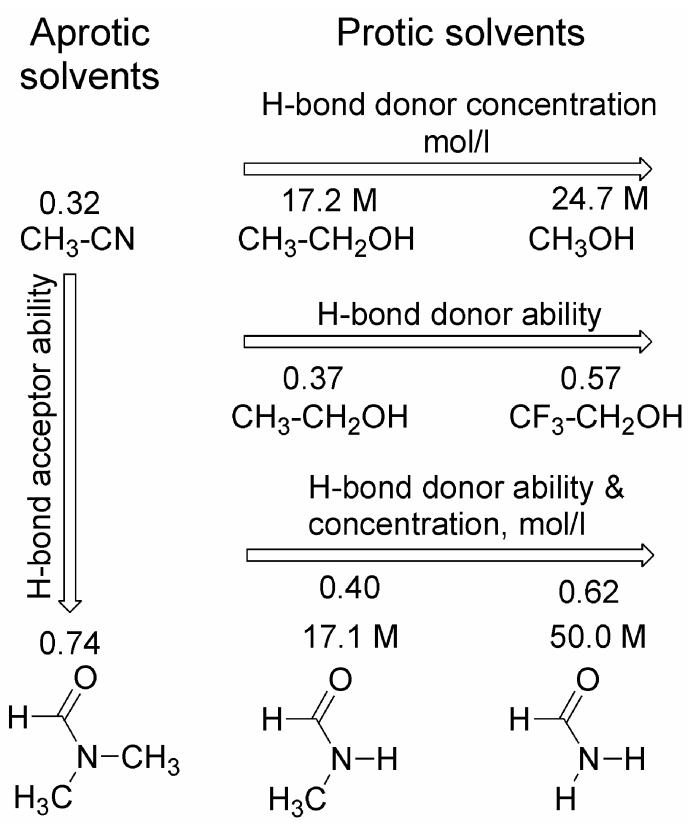

Figure 2. Solvents used in the present study and their classification by their physicochemical properties. 
Table 1. Spectroscopic properties of $3 \mathrm{HC}$ dyes in different polar solvents. ${ }^{\text {a }}$

\begin{tabular}{|c|c|c|c|c|c|c|c|c|}
\hline Solvent & $3 \mathrm{HC}$ dye & $\mathrm{MeCN}^{\mathrm{b}}$ & $\mathrm{EtOH}^{\mathrm{b}}$ & $\mathrm{MeOH}^{\mathrm{b}}$ & TFE & DMF & $\mathrm{MF}$ & $\mathrm{F}$ \\
\hline$f(\varepsilon)$ & & 0.4802 & $0 \cdot 4704$ & 0.4774 & 0.4725 & $0 \cdot 4798$ & 0.4959 & 0.4932 \\
\hline$\alpha$ & & $0 \cdot 07$ & $0 \cdot 37$ & 0.43 & 0.57 & 0 & $0 \cdot 4$ & $0 \cdot 62$ \\
\hline$\beta$ & & $0 \cdot 32$ & $0 \cdot 48$ & 0.47 & $0 \cdot 25$ & 0.74 & $0 \cdot 55$ & 0.6 \\
\hline$\lambda_{\max }^{\mathrm{abs}} / \mathrm{nm}$ & $\begin{array}{l}1 \\
2 \\
3\end{array}$ & $\begin{array}{l}339 \\
348 \\
358\end{array}$ & $\begin{array}{l}343 \\
357 \\
366\end{array}$ & $\begin{array}{l}343 \\
356 \\
370\end{array}$ & $\begin{array}{l}344 \\
295^{\mathrm{d}} \\
364\end{array}$ & $\begin{array}{l}344 \\
354 \\
363\end{array}$ & $\begin{array}{l}344 \\
356 \\
366\end{array}$ & $\begin{array}{l}345^{\mathrm{c}} \\
364^{\mathrm{c}} \\
370^{\mathrm{c}}\end{array}$ \\
\hline$\lambda_{\max }^{N^{*}} / \mathrm{nm}$ & $\begin{array}{l}1 \\
2 \\
3\end{array}$ & $\begin{array}{l}394 \\
409 \\
418\end{array}$ & $\begin{array}{l}402 \\
416 \\
425\end{array}$ & $\begin{array}{l}403 \\
416 \\
428\end{array}$ & $\begin{array}{l}405 \\
422 \\
443\end{array}$ & $\begin{array}{l}401 \\
418 \\
422\end{array}$ & $\begin{array}{l}401 \\
424 \\
431\end{array}$ & $\begin{array}{l}403 \\
426 \\
436\end{array}$ \\
\hline$\lambda_{\max }^{T^{*}} / \mathrm{nm}$ & $\begin{array}{l}1 \\
2 \\
3\end{array}$ & $\begin{array}{l}525 \\
533 \\
542\end{array}$ & $\begin{array}{l}532 \\
531 \\
543\end{array}$ & $\begin{array}{l}528 \\
527 \\
540\end{array}$ & $\begin{array}{r}501 \\
- \\
510\end{array}$ & $\begin{array}{l}535 \\
439 \\
550\end{array}$ & $\begin{array}{l}532 \\
536 \\
546\end{array}$ & $\begin{array}{l}523 \\
527 \\
538\end{array}$ \\
\hline$I_{\mathrm{N}^{*}} / I_{\mathrm{T}^{*}}$ & $\begin{array}{l}1 \\
2 \\
3\end{array}$ & $\begin{array}{c}0 \cdot 028 \\
0 \cdot 098 \\
0 \cdot 040\end{array}$ & $\begin{array}{l}0.270 \\
0.644 \\
0.220\end{array}$ & $\begin{array}{l}0.442 \\
1 \cdot 71 \\
0.570\end{array}$ & $\begin{array}{l}0 \cdot 60 \\
6 \cdot 6 \\
2 \cdot 12\end{array}$ & $\begin{array}{l}0.058 \\
0.127 \\
0.064\end{array}$ & $\begin{array}{l}0.22 \\
0.420 \\
0 \cdot 164\end{array}$ & $\begin{array}{l}0.27 \\
1.58 \\
0.536\end{array}$ \\
\hline$\phi(\%)$ & $\begin{array}{l}1 \\
2 \\
3\end{array}$ & $\begin{array}{r}5 \\
6 \\
17\end{array}$ & $\begin{array}{r}3 \\
8 \\
15\end{array}$ & $\begin{array}{r}3 \\
8 \\
18\end{array}$ & $\begin{array}{r}5 \\
9 \\
26\end{array}$ & $\begin{array}{c}1 \cdot 3 \\
7 \\
10\end{array}$ & $\begin{array}{r}3 \\
8 \\
18\end{array}$ & $\begin{array}{r}4 \\
10 \\
18\end{array}$ \\
\hline
\end{tabular}

${ }^{\mathrm{a}} f(\varepsilon)$ - solvent polarity as a function of dielectric constant, $f(\varepsilon)=(\varepsilon-1) /(2 \varepsilon+1) ; \alpha$ and $\beta$ - Abraham's H-bond acidity and basicity, respectively, introduced in refs. [31] and [32], $\lambda_{\max }^{\mathrm{abs}}-$ position of the absorption maximum; $\lambda_{\max }^{\mathrm{N}^{*}}$ and $\lambda_{\max }^{\mathrm{T}^{*}}-$ position of the fluorescence maxima of $N^{*}$ and $T^{*}$ forms, respectively; $\phi$ is the fluorescence quantum yield. ${ }^{b} \mathrm{Data}$ from ref. [25]. ${ }^{\mathrm{c}}$ The long-wavelength absorption band of the dye overlaps with the absorption spectrum of the anionic form in this solvent. ${ }^{\mathrm{d}}$ The long-wavelength absorption band appears as a shoulder in this solvent. Thus, in this case, the position of the central absorption peak is presented.

The solutions of $3 \mathrm{HC}$ derivatives for absorption and fluorescence spectroscopy were used at concentrations (around $5 \mu \mathrm{M}$ ) corresponding to an absorbance close to $0 \cdot 1$. Quantum yields $\phi$ of the dyes were determined with respect to a solution of $\mathbf{1}$ in toluene as a reference $(\phi=0 \cdot 29){ }^{33}$

\section{Results and discussion}

In the present work, a variety of polar organic solvents has been used, which can be divided into aprotic and protic (figure 2). The aprotic solvents, acetonitrile and N,N-dimethylformamide are of similar polarity, but differ in their $\mathrm{H}$-bond acceptor ability (table 1). The protic solvents used can be classified into three couples: (1) ethanol-methanol which differ by their $\mathrm{H}$-bond donor ( $\mathrm{OH}$-protons) concentrations, (2) ethanol-2,2,2-trifuoroethanol (TFE) which are structurally close alcohols of different $\mathrm{H}$-bond donor abilities and (3) N-methylformamide (MF)-formamide (F) where the H-bond donor (NH-proton) concentration and $\mathrm{H}$-bond donor ability vary simultaneously. Note that the third couple corresponds to amides which are significantly different $\mathrm{H}$-bond donors as compared to alcohols.
In the absorption spectra of dyes $\mathbf{1 - 3}$, we observe a single band which does not vary systematically with the solvent properties (table 1). Only in formamide, we observe a significant fraction of a long-wavelength band $(410-430 \mathrm{~nm})$, which corresponds to the absorption of the deprotonated (anionic) form of the dyes (not shown). Meantime, two emission bands are observed in the emission spectra of dyes 1-3 in all the solvents the studied. This is an indication of an ESIPT reaction, in line with previous studies of these compounds. ${ }^{1,24,25,30}$

The fluorescence quantum yields $\phi$ of dyes $\mathbf{1}-\mathbf{3}$ do not vary systematically with the solvents. However, as a general trend, we note that the highest $\phi$ values are observed in the highly $\mathrm{H}$-bond acidic TFE, while the lowest $\phi$ values are detected in DMF, which is characterized by large H-bond acceptor ability (table 1). These observations may be related to the ability of H-bond basic solvents to disrupt the intramolecular $\mathrm{H}$-bond of $3 \mathrm{HCs}$ and form non-emissive species. ${ }^{30}$

In aprotic solvents, the relative intensity of the $\mathrm{N}^{*}$ band is very weak as compared to that of the $\mathrm{T}^{*}$ band for all three dyes. In this case, the strong $\mathrm{T}^{*}$ emission results from an extremely fast ESIPT reaction which nearly completely transforms the $\mathrm{N}^{*}$ state into the 
$\mathrm{T}^{*}$ state. ${ }^{34}$ Notably, the relative intensity of the $\mathrm{N}^{*}$ band is low both in acetonitrile and DMF, two solvents of very different $\mathrm{H}$-bond acceptor abilities (table 1), indicating that dyes $\mathbf{1}-\mathbf{3}$ are not very sensitive to this solvent property. This conclusion is in line with previous studies of 4'-(diethylamino)-3-hydroxyflavone, a derivative of compound 1 . $^{2}$ In all the protic solvents studied, the relative intensity of the $\mathrm{N}^{*}$ emission band, expressed as the intensity ratio $I_{\mathrm{N}^{*}} I_{\mathrm{T}^{*}}$, is significantly larger than in aprotic solvents (figures 3 and 4, table 1). Thus, H-bond donors probably inhibit the ESIPT reaction of $3 \mathrm{HCs}^{2,29}$ Further increase in the concentration of the $\mathrm{H}$-bond donors from ethanol to methanol also results in strong increase in the $I_{\mathrm{N}^{*}} / I_{\mathrm{T}^{*}}$ ratio (figure 3). In contrast, the positions of the emission band maxima for all three dyes are nearly not affected since only a small $(3-4 \mathrm{~nm})$ blue shift of the $\mathrm{T}^{*}$ band is observed. The increase in the H-bond donor ability from ethanol to TFE results in strong increase in the $I_{\mathrm{N}^{*}} / I_{\mathrm{T}^{*}}$ intensity ratio (figure 3 ), which is accompanied by red shift of the $\mathrm{N}^{*}$ emission band (table 1). Moreover, in the highly $\mathrm{H}$-bond acidic TFE, we observe a strong blue shift (ca $30 \mathrm{~nm}$ ) and a significant broadening of the $\mathrm{T}^{*}$ emission band (figure 3). Noticeably, the increase in H-bond acidicity from ethanol to TFE affects the dual emission of dyes $\mathbf{2}$ and $\mathbf{3}$ to a much larger extent than that of dye $\mathbf{1}$.

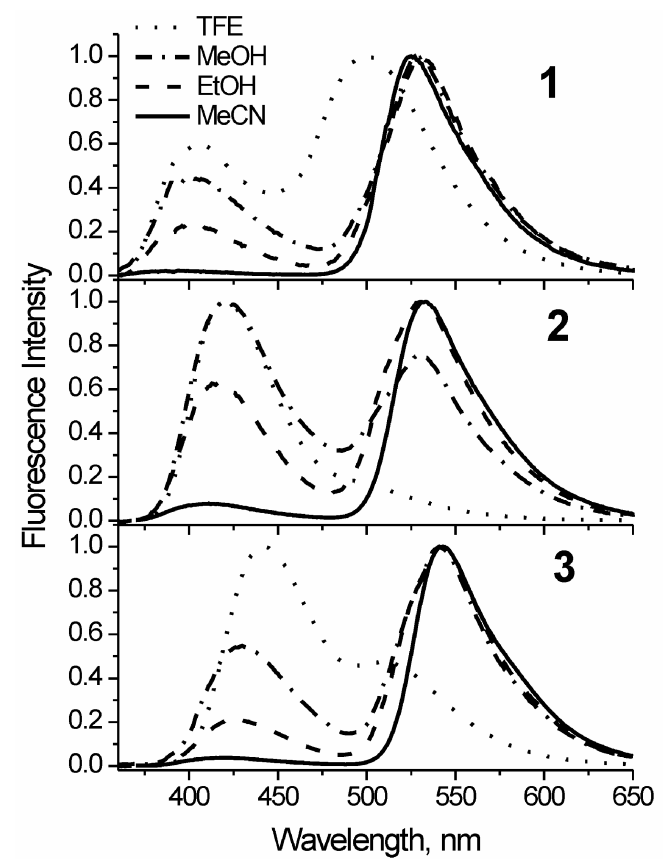

Figure 3. Normalized fluorescence spectra of dyes 1-3 in acetonitrile $(\mathrm{MeCN})$ and different alcohols: ethanol $(\mathrm{EtOH})$, methanol $(\mathrm{MeOH})$ and 2,2,2-trifluoroethanol (TFE). Excitation wavelength was $350 \mathrm{~nm}$.
When the protic amides are compared, we observe that the $I_{\mathrm{N}^{*}} / I_{\mathrm{T}^{*}}$ ratio for all three dyes increases strongly from MF to F (figure 4). This effect is in accordance with the observation in alcohols, so that both increase in H-bond donor ability and donor concentration contribute to the observed increase in the $I_{\mathrm{N}^{*}} / I_{\mathrm{T}^{*}}$ ratio. Moreover, we also observe for all dyes a regular shift of the $T^{*}$ emission to the blue $(8-9 \mathrm{~nm})$ from MF to $F$, in line with the effect of the increase in H-bond acidicity seen in alcohols. Interestingly, we also observe that in the different amides, the increase of the $I_{\mathrm{N}^{*}} / I_{\mathrm{T}^{*}}$ ratio is far weaker for dye 1 than for dyes $\mathbf{2}$ and $\mathbf{3}$.

To characterize quantitatively the differences in sensitivity of the studied dyes to the solvent properties, we plotted the $I_{\mathrm{N}^{*}} / I_{\mathrm{T}^{*}}$ ratio in a logarithmic scale (figure 5), according to our well-established methodology.,24 It can be seen that $\log \left(I_{\mathrm{N}^{*}} / I_{\mathrm{T}^{*}}\right)$ increases to a similar extent for all three dyes on transition from aprotic to protic solvents or with the increase in $\mathrm{H}$-bond donor concentration from ethanol to methanol. In contrast, the increase in $\mathrm{H}$-bond donor ability from ethanol to TFE and from MF to F results in an increase of the $I_{\mathrm{N}^{*}} / I_{\mathrm{T}^{*}}$ ratio which is much stronger for dyes $\mathbf{2}$ and $\mathbf{3}$ than for dye $\mathbf{1}$. Thus, while $3 \mathrm{HC}$ dyes $\mathbf{1}-\mathbf{3}$ show a similar sensitivity of their dual emission to the $\mathrm{H}$ bond donor concentration, dyes $\mathbf{2}$ and $\mathbf{3}$ show a

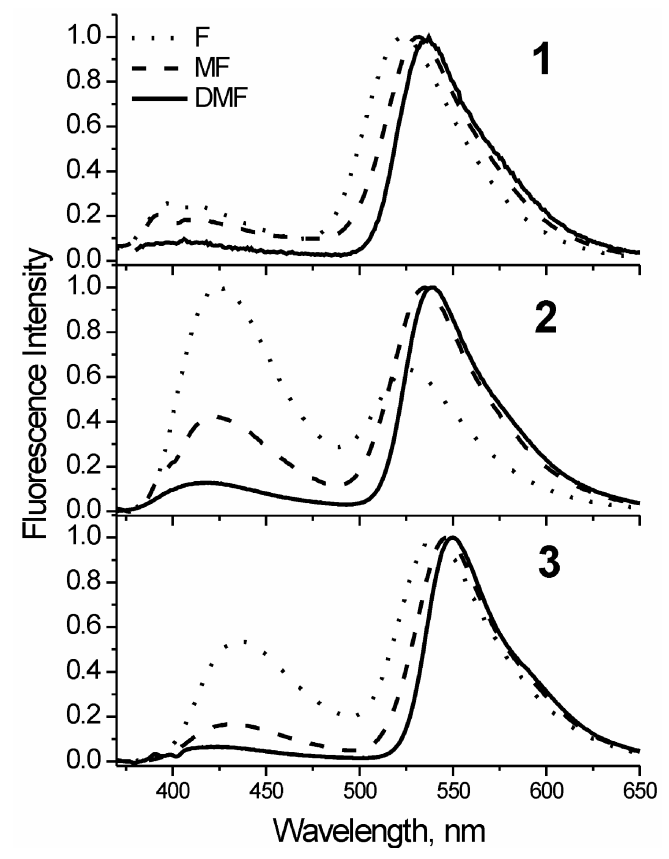

Figure 4. Normalized fluorescence spectra of dyes 1-3 in different amide-based solvents: formamide (F), N-methylformamide (MF) and N,N-dimethylformamide (DMF). Excitation wavelength was $350 \mathrm{~nm}$. 
much higher sensitivity than dye $\mathbf{1}$ to the H-bond donor ability of the solvents.

How do H-bond donor ability and donor concentration affect the relative intensities of the two bands, and why do compounds $\mathbf{2}$ and $\mathbf{3}$ show different sensitivities as compared to the parent dye 1? It has already been established that intermolecular H-bonds with the solvent may strongly uncouple the ESIPT reaction. ${ }^{29}$ In this respect, intermolecular H-bonds with alcohols may disrupt the intramolecular $\mathrm{H}$ bond of dyes 1-3 (figure 6a) and uncouple the ESIPT process as was described in alcohol glasses ${ }^{23}$ or provide a slow ESIPT through solvent pathway. ${ }^{29,35,36}$ The uncoupling or the slowing down of the ESIPT reaction may explain the observed increase in the relative intensity of the $\mathrm{N}^{*}$ emission in protic solvents with respect to aprotic solvents as well as its increase with the H-bond donor concentration. In contrast, this cannot explain the higher sensitivity to the H-bond donor ability of compounds $\mathbf{2}$ and $\mathbf{3}$ with respect with the parent dye $\mathbf{1}$. Moreover, in the highly $\mathrm{H}$-bond acidic TFE, the disruption of the intramolecular $\mathrm{H}$-bond is less favourable than in the other alcohols since its hydroxyl group is far less basic and thus, would form much weaker intermolecular $\mathrm{H}$-bonds with the 3-OH group of the dyes. Finally, in amide solvents, the H-bond network is different from that in alcohols, since their H-bond donor (NH hydrogen) and H-bond acceptor (carbonyl oxygen) are more separated than in alcohols. Despite these differences, the spectroscopic effects in amide solvents are similar to those in alcohols, suggesting that additional $\mathrm{H}$ -

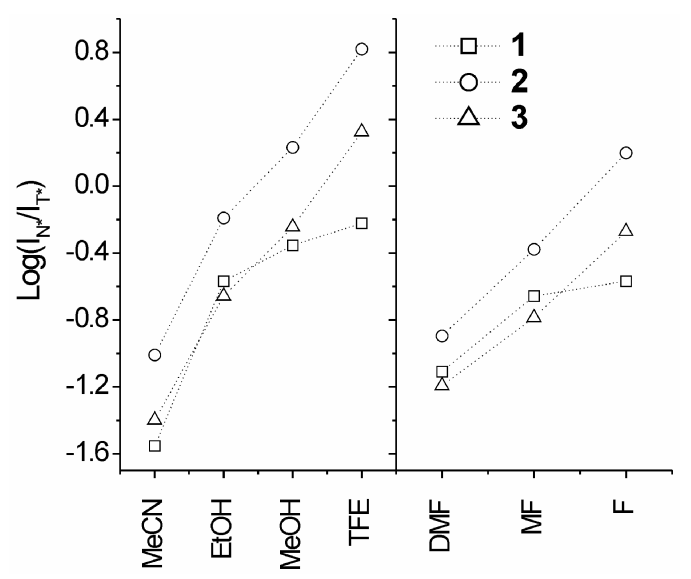

Figure 5. Logarithms of the intensity ratios of the two emission bands, $I_{\mathrm{N}^{*}} / I_{\mathrm{T}^{*}}$, in different solvents. In these two diagrams, the solvents are grouped and ordered with respect to their H-bond bond donor ability and/or H-bond donor concentration. bonded structures should also be considered. In this respect, structures with preserved intramolecular $\mathrm{H}$ bonds are perhaps involved (figure 6b). In these structures, intermolecular $\mathrm{H}$-bonds probably form between the acidic hydrogen of the solvent and the free electron pair of the 4-carbonyl group; the strength of the intermolecular $\mathrm{H}$-bond being directly correlated to the H-bond acidicity of the solvents. Previously, the formation of such an H-bond was shown to affect dual emissions significantly and the ESIPT kinetics of analogues of $\mathbf{1}$ that are characterized by a significant charge transfer of their $\mathrm{N}^{*}$ excited state. ${ }^{2,37,38}$ However, in the case of the parent dye 1 , the $\mathrm{N}^{*}$ state exhibits a relatively small dipole moment which explains the rather weak dependence of its $\mathrm{N}^{*}$ band position on the solvent polarity. ${ }^{24,39}$ In contrast, dyes 2 and 3, bearing electron donor furan and benzofuran rings, respectively, may undergo a partial charge transfer in their $\mathrm{N}^{*}$ excited state, which explains the stronger dependence of their $\mathrm{N}^{*}$ band on the solvent polarity. ${ }^{24,39}$ Moreover, the flatter structure of compounds $\mathbf{2}$ and $\mathbf{3}$ with respect to $\mathbf{1}$ probably further favors the charge transfer due to higher conjugation between the electron donor furan/benzofuran and electron acceptor $3 \mathrm{HC}$ units. ${ }^{39}$ This increased charge transfer in dyes $\mathbf{2}$ and $\mathbf{3}$ should thus in turn favour intermolecular $\mathrm{H}$-bonding with the solvent due to an increase of the partial negative charge at their 4 -carbonyl oxygen.

Formation of this H-bond explains the red shifts of the $\mathrm{N}^{*}$ emission band with increase in the $\mathrm{H}$-bond donor ability of the solvents, which are observed for<smiles>[R]O[14CH2]Oc1c(-c2ccccc2)oc2ccccc2c1=O</smiles><smiles>[R]O[C@@H]1Oc2ccccc2C(=O)[C@H](O[R])O1</smiles><smiles>[R]O[C@H](O)[C@H]1O[C@@H](c2ccccc2)C(c2ccccc2)Oc2ccccc21</smiles>

Figure 6. Possible H-bonded forms of dye 1 with alcohols. 
dyes $\mathbf{2}$ and $\mathbf{3}$, but is almost not seen for dye $\mathbf{1}$. Moreover, the H-bonding of the dyes with solvents of high H-bond donor ability should weaken the intramolecular H-bonds and thus decrease the ESIPT rates. This prediction is in line with the dramatic increase of $\mathrm{N}^{*}$ emission with respect to $\mathrm{T}^{*}$ emission in solvents of increasing $\mathrm{H}$-bond donor ability. Thus, our data suggest that the higher sensitivity of the dual emission of dyes $\mathbf{2}$ and $\mathbf{3}$ to the H-bond donor ability of solvents, is connected with the increased charge transfer character of their $\mathrm{N}^{*}$ excited state.

Interestingly, dye 1 exhibits high sensitivity to $\mathrm{H}$ bond donor concentration, which is comparable to that of dyes 2 and 3 (figure 5). This indicates that a different mechanism is responsible for the variation of the dual emission in this case. This different mechanism is also suggested by the relatively small variations in the position of $\mathrm{N}^{*}$ and $\mathrm{T}^{*}$ bands with variation of $\mathrm{H}$-bond donor concentration, in contrast to the strong effects of the H-bond donor ability (table 1). The absence of significant spectral shifts is in favour of structures with disrupted intramolecular $\mathrm{H}$ bonds (figure $6 \mathrm{a}$ ) which should not significantly modify the energy of the states, but should increase the barrier for the ESIPT reaction. These structures probably dominate in dye 1 , since its $\mathrm{N}^{*}$ emission band is nearly invariant in the studied solvents. Meantime, in dyes $\mathbf{2}$ and $\mathbf{3}$, both types of structures (figures $6 \mathrm{a}$ and $\mathrm{b}$ ) are probably responsible for the observed changes of the dual emission. Indeed, the structures in Figure 6a are probably responsible for the effect of the H-bond concentration, while structures with preserved intramolecular $\mathrm{H}$-bonds play a major role for the effects of the H-bond donor ability.

In conclusion, three different $3 \mathrm{HC}$ derivatives have been studied in polar solvents. While the H-bond acceptor ability of the solvents weakly affects the dual emissions of the dyes, the H-bond donor properties of the solvents significantly modify the emissions. Thus, the increase in the H-bond donor concentration increases the $I_{\mathrm{N}^{*}} / I_{\mathrm{T}^{*}}$ ratio for all the dyes but does not affect the position of their emission bands. These effects are related to the disruption of the intramolecular H-bond of the dyes by protic solvents. Meantime, the increase in the $\mathrm{H}$-bond donor ability of the solvents results both in increase of the $I_{\mathrm{N}^{*}} / I_{\mathrm{T}^{*}}$ ratio and shifts of the emission bands; these effects being more pronounced for furyl- and benzofurylsubstituted 3HCs. These effects are related to the increase in the strength of the H-bonds between the solvents and the 4-carbonyl group of dyes with intact intramolecular H-bonds. Our results provide insights for further applications of $3 \mathrm{HC}$ derivatives as environment-sensitive probes and labels for biological applications.

\section{Acknowledgements}

This work was supported by grants from the CNRS, Université Louis Pasteur and the European Community (TRIoH integrated project). C K was a fellow from TRIoH.

\section{References}

1. Sengupta P K and Kasha M 1979 Chem. Phys. Lett. 68382

2. Klymchenko A S and Demchenko A P 2003 Phys. Chem. Chem. Phys. 5461

3. Bright G R, Fisher G W, Rogowska J and Taylor D L 1989 Methods Cell Biol. 30157

4. Silver R B 1998 Methods Cell Biol. 56237

5. Ercelen S, Klymchenko A S and Demchenko A P 2002 Anal. Chim. Acta 464273

6. Liu W, Wang Y, Jin W, Shen G and Yu R 1999 Anal. Chim. Acta 383299

7. Roshal A D, Grigorovich A V, Doroshenko A O, Pivovarenko V G and Demchenko A P 1998 J. Phys. Chem. A102 5907

8. Klymchenko A S and Demchenko A P $2002 \mathrm{~J}$. Am. Chem. Soc. 12412372

9. Klymchenko A S, Duportail G, Mély Y and Demchenko A P 2003 Proc. Natl. Acad. Sci. USA 100 11219

10. Dharia J R, Johnson K F and Schlenoff J B 1994 Macromolecules 275167

11. Dennison S M, Guharay J and Sengupta P K 1999 Spectrochim. Acta A55 1127

12. Klymchenko A S and Demchenko A P 2002 Langmuir 185637

13. Tormo L and Douhal A 2005 J. Photochem. Photobiol. A173 358

14. Bondar O P, Pivovarenko V G and Rowe E S 1998 Biochim. Biophys. Acta 1369119

15. Klymchenko A S, Duportail G, Oztürk T, Pivovarenko V G, Mély Y and Demchenko A P 2002 Chem. Biol. 91199

16. Klymchenko A S, Duportail G, Demchenko A P and Mély Y 2004 Biophys. J. 862929

17. Klymchenko A S, Mély Y, Demchenko A P and Duportail G 2004 Biochim. Biophys. Acta 16656

18. Shynkar V V, Klymchenko A S, Duportail G, Demchenko A P and Mély Y 2005 Biochim. Biophys. Acta 1712128

19. Ercelen S, Klymchenko A S and Demchenko A P 2003 FEBS Lett. 53825

20. Klymchenko A S, Avilov S V and Demchenko A P 2004 Anal. Biochem. 32943 
21. Avilov S V, Bode C, Tolgyesi F G, Klymchenko A S, Fidy J and Demchenko A P 2005 Int. J. Biol. Macromol. 36290

22. Guharay J, Sengupta B and Sengupta P K 2001 Proteins: Struct., Function Genet. $\mathbf{4 3} 75$

23. Sytnik A, Gormin D and Kasha M 1994 Proc. Natl. Acad. Sci. USA 9111968

24. Klymchenko A S, Pivovarenko V G, Oztürk T and Demchenko A P 2003 New J. Chem. 271336

25. Klymchenko A S and Demchenko A P 2004 New J. Chem. 28687

26. Reichardt C 1994 Chem. Rev. 942319

27. Strandjord A J G and Barbara P F 1985 J. Phys. Chem. 892355

28. Swinney T C and Kelley F D 1993 J. Chem. Phys. 99211

29. McMorrow D and Kasha M 1984 J. Phys. Chem. 88 2235

30. Klymchenko A S, Pivovarenko V G, and Demchenko A P 2003 Spectrochim. Acta A59 787
31. Abraham M H 1993 J. Phys. Org. Chem. 6660

32. Abraham $M \mathrm{H}$, Chadha $\mathrm{H} \mathrm{S}$, Whiting $\mathrm{G} S$ and Mitchell R C 1994 J. Pharm. Sci. 831085

33. Ormson, S M, Brown R G, Volmer F Rettig J $1994 J$. Photochem. Photobiol. A81 65

34. Ameer-Beg S, Ormson S M, Brown R G, Matousek P, Towrie M, Nibbering E T J, Foggi P and Neuwahl F V R 2001 J. Phys. Chem. A105 3709

35. Strandjord A J G and Barbara P F 1984 J. Phys. Chem. 892355

36. Woolfe G J and Thistlethwaite P J $1981 \mathrm{~J}$. Am. Chem. Soc. 1036916

37. Klymchenko A S, Pivovarenko V G and Demchenko A P 2003 J. Phys. Chem. A107 4211

38. Shynkar V V, Klymchenko A S, Piemont E, Demchenko A P and Mely Y 2004 J Phys. Chem. A108 8151

39. Yesylevskyy S O, Klymchenko A S and Demchenko A P 2005 J. Mol. Struct. (Theochem.) 755229 